\title{
Catabolite Repression in Antibiotic-limited Streptomycin-dependent Escherichia coli B
}

\author{
By M. B. COUKELL AND W. J. POL GLASE \\ Department of Biochemistry, University of British Columbia, Vancouver, Canada
}

(Accepted for publication 3 May 1969)

\begin{abstract}
SUMMARY
The half-maximal growth rate of a streptomycin-dependent mutant of Escherichia coli B on limiting concentrations of dihydrostreptomycin varied with the nature (but not with the initial concentration) of the carbon source. It was highest with gluconate, lower with glucose and glycerol and lowest with lactate. Glucose-sensitive enzymes (acetohydroxy acid synthetase, fumarase, aconitase, citrate synthase and isocitric dehydrogenase) were specifically repressed by antibiotic limitation. Parallelism was observed between decreasing dihydrostreptomycin concentration, decreasing growth rate and increasing catabolite repression of certain glucose-sensitive enzymes. The results are not incompatible with the hypothesis that the primary site of action of dihydrostreptomycin in the dependent organism is an anabolic process (e.g. protein synthesis). However, the growth-limiting effect of antibiotic deprival appears to be augmented by catabolite repression.
\end{abstract}

\section{INTRODUCTION}

A recent publication from this laboratory (Coukell \& Polglase, 1969b) reported that a number of catabolite repression-sensitive enzymes were specifically derepressed in a streptomycin-dependent mutant of Escherichia coli B growing exponentially in a medium containing a non-limiting concentration of antibiotic. Relaxation of catabolite repression in this mutant was attributed to a deficiency in glucose metabolism observed through a study of cell yields (Coukell \& Polglase, 1969b). One of the enzymes derepressed in this streptomycin-dependent mutant was the glucosesensitive acetohydroxy acid (AHA) synthetase (Coukell \& Polglase, I969a), a biosynthetic enzyme involved in the formation of the aliphatic amino acids (valine, leucine and isoleucine) and pantothenate (Umbarger \& Davis, 1962). Earlier studies on AHA synthetase in a streptomycin-dependent strain of $E$. coli grown with limiting antibiotic indicated that the formation of this enzyme was strongly repressed and that the degree of repression was inversely related to the concentration of antibiotic on which the culture was grown (Polglase, 1966). The present study reports an investigation of the effect of antibiotic-limitation on the growth of a streptomycin-dependent mutant of $E$. coli and on catabolite repression in these cells.

\section{METHODS}

Organisms. Wild-type Escherichia coli в (ATCC I 1303) and a spontaneous streptomycin-dependent mutant derived from this organism (Coukell \& Polglase, I965), were used throughout this work. 
Media, cultures and extraction. Cultures were grown on a minimal salts medium described by Davis \& Mingioli (1950) but with the omission of citrate. The carbon source (glucose, sodium gluconate, glycerol or sodium lactate) and dihydrostreptomycin sulphate were autoclaved separately in concentrated solution and added to the minimal medium. Growth was determined turbidimetrically at $420 \mathrm{~m} \mu$ in a Beckman B spectrophotometer (light path, $\mathrm{I} \cdot 0 \mathrm{~cm}$.). The procedures for growing streptomycinsensitive cultures, and for growing streptomycin-dependent cultures on non-limiting concentrations ( $>100 \mu \mathrm{g} . / \mathrm{ml}$.) of antibiotic, and the procedures for harvesting cultures and for preparation of crude sonic extracts have been described previously (Coukell \& Polglase, I969a). All cultures were grown at $37^{\circ}$ with vigorous aeration.

Growth of antibiotic-limited and depleted cells. The streptomycin-dependent strain was grown in approximately $50 \mathrm{ml}$. of minimal salts medium containing $30 \mu \mathrm{g}$. of dihydrostreptomycin $/ \mathrm{ml}$. and the appropriate carbon source at $37^{\circ}$ without agitation for 24 to $48 \mathrm{hr}$. A portion ( 2 to $4 \mathrm{ml}$.) of this culture was transferred to another $50 \mathrm{ml}$. of similar medium and the procedure was repeated. After three or four such transfers, the entire culture $(50 \mathrm{ml}$.) was added to $500 \mathrm{ml}$. of similar medium and grown for $\mathrm{I} 8 \mathrm{hr}$ at $37^{\circ}$. The resulting bacteria were centrifuged at $16,000 \mathrm{~g}$ for $20 \mathrm{~min}$. and resuspended in 61 . of fresh, warm $\left(37^{\circ}\right)$ medium to give an $E_{420}$ of approximately 0.I. The culture was divided into six I 1 . volumes, and supplemented with the required amount of dihydrostreptomycin (usually in the range of 3 to $25 \mu \mathrm{g}$. $/ \mathrm{ml}$.). A carbon source was added and the cultures were grown with forced aeration to an $E_{420}$ of 0.9 to $\mathrm{I} \cdot 0$. The bacteria were harvested and stored as described by Coukell \& Polglase (I969a). Bacteria grown in this way are referred to as 'antibiotic-limited, streptomycindependent'. Bacteria referred to as 'antibiotic-depleted streptomycin-dependent' were obtained by growth of the mutant on antibiotic-free medium as described by Bragg \& Polglase (1963).

Enzyme assays. All enzyme activities were determined on crude ultrasonic extracts. AHA-synthetase activity was measured in fresh extracts as described elsewhere (Coukell \& Polglase, 1969a). One unit of activity is equivalent to the formation of I $\mu$ mole acetoin $/ \mathrm{hr}$ at $37^{\circ}$. Fumarase and aconitase activities were determined spectrophotometrically on fresh extracts at $240 \mathrm{~m} \mu$ as described by Hanson \& Cox (1967). A unit of activity for each enzyme is defined as an extinction change of $0.001 /$ min. Isocitric dehydrogenase, glucose-6-phosphate dehydrogenase (Coukell \& Polglase, 1969b) and glucokinase (Coukell \& Polglase, 1965) activities were estimated on fresh extracts or on extracts which had been stored at $-20^{\circ}$ for not more than $48 \mathrm{hr}$. A unit of activity for each enzyme is equivalent to the formation of I m $\mu$ mole NADPH/min. The condensing enzyme, citrate synthase, was determined spectrophotometrically in extracts by measuring the change in extinction at $233 \mathrm{~m} \mu$ (Coukell \& Polglase, 1969a). A unit of enzyme activity is equivalent to the amount of enzyme which catalyses the formation of I $\mathrm{m} \mu$ mole citrate/min. All spectrophotometric determinations were made with a Cary 15 recording spectrophotometer at $25^{\circ}$. Specific activities were expressed as units enzyme $/ \mathrm{mg}$. of protein. Protein was estimated by the procedure of Lowry, Rosebrough, Farr \& Randall (I95I), with bovine $\gamma$-globulin as a standard.

Chemicals. Dihydrostreptomycin sulphate was a gift from Merck, Sharp and Dohme, Montreal, Canada. All other chemicals were obtained from Calbiochem., Los Angeles. 


\section{RESULTS}

Antibiotic-requirement for growth on various carbon sources. Preliminary experiments indicated that the streptomycin-dependent mutant, which was isolated initially on medium containing I $\mathrm{mg}$. dihydrostreptomycin $/ \mathrm{ml}$., had comparable growth rates at dihydrostreptomycin concentrations of $\mathrm{I} \mathrm{mg} . / \mathrm{ml}$. or $100 \mu \mathrm{g} . / \mathrm{ml}$. Below $50 \mu \mathrm{g} . / \mathrm{ml}$., however, the growth rate of this mutant was diminished (Fig. I). When antibiotic was not added to the culture, only slight growth occurred during the period

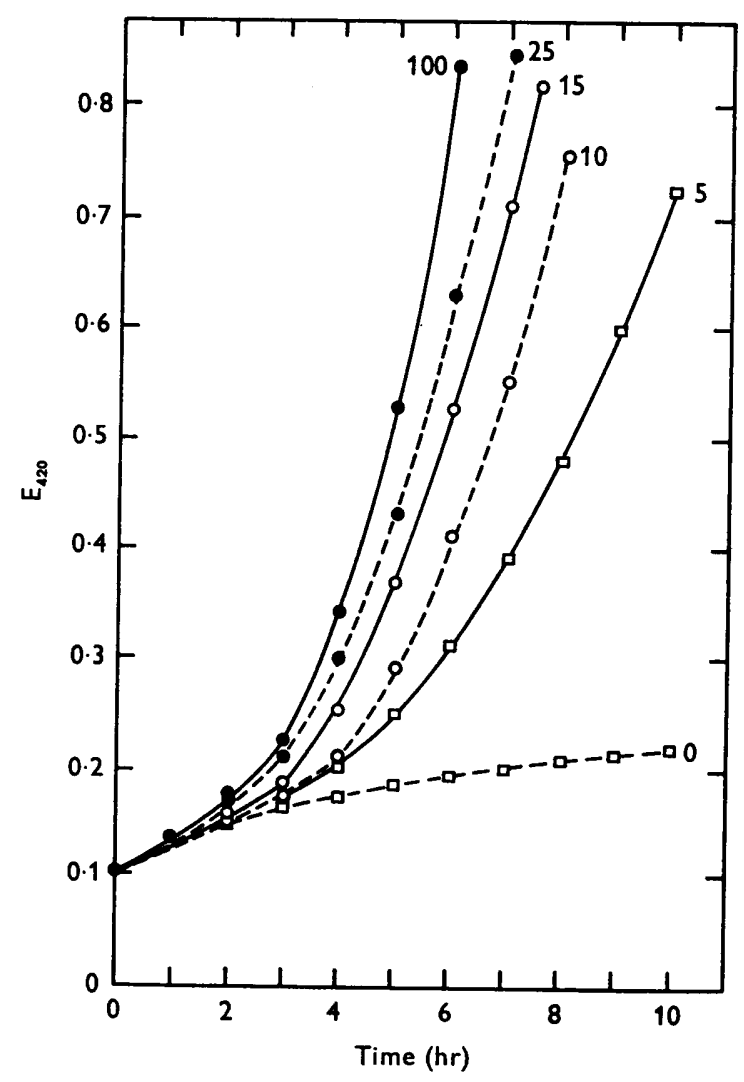

Fig. I. Growth curves for streptomycin-dependent Escherichia coli B growing on glucose $(0.4 \%$, w/v) salts medium supplemented with rate-limiting concentrations of dihydrostreptomycin. The numbers on each curve indicate the concentration $(\mu \mathrm{g} . / \mathrm{ml}$.) of antibiotic added at zero time. Further experimental details are given in Methods.

of incubation. Cultures with 5 to $100 \mu \mathrm{g}$. dihydrostreptomycin/ml. exhibited exponential growth. When the growth rates of these cultures were plotted against the concentration of antibiotic on which they were grown, a hyperbolic, saturation curve was obtained (Fig. 2A). The corresponding double reciprocal plot of these data is shown in Fig. $2 \mathrm{~B}$ from which two constants may be calculated: $\mathrm{K}_{\mathrm{DH} \mathrm{m}}$, equivalent to the concentration of dihydrostreptomycin which permitted half the maximum growth rate, and $\mathbf{V}_{\max }$, the growth rate at a non-limiting concentration of dihydrostrepto- 
mycin. With glucose as the carbon source, $K_{D H s m}$ and $V_{\max }$ were $5.3 \mu \mathrm{g} . / \mathrm{ml}$. and $0.645 \mathrm{hr}^{-1}$ respectively.

A tenfold increase in initial glucose concentration had no significant effect on $\mathbf{K}_{\mathrm{DHBm}}$ but increased $\mathrm{V}_{\max }$. $\mathbf{K}_{\mathrm{DHSm}}$ and $\mathrm{V}_{\max }$ values obtained employing different carbon sources are listed in Table $I$. Average $K_{\mathrm{DHsm}}$ values ranged from 12.6 when gluconate was the carbon source to $\mathrm{I} \cdot 5$ with lactate. Thus, in order to attain one-half maximal growth rates, 8.4 times as much dihydrostreptomycin was needed when gluconate was the carbon source as when lactate was used. The order of increasing growth rate was lactate $<$ glycerol $<$ glucose $<$ gluconate, the same order as the $\mathrm{K}_{\mathrm{DHAm}}$ values. The values obtained for $\mathrm{K}_{\mathrm{DH} \text { m }}$ and $\mathrm{V}_{\max }$ were highly reproducible.
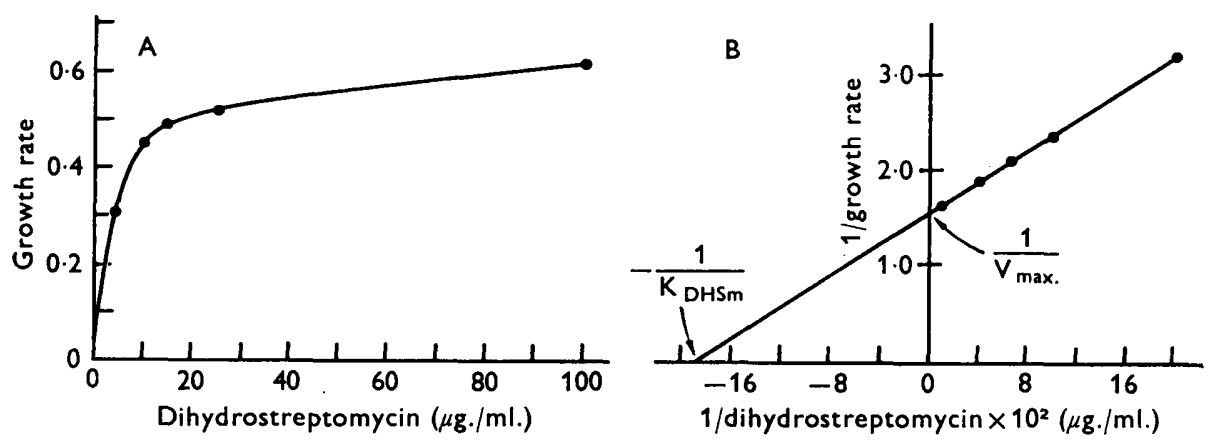

Fig. 2. Relationship between the growth rate of streptomycin-dependent Escherichia coli and the concentration of dihydrostreptomycin in the medium. The data were obtained from the experiment shown in Fig. I. A, Plot of growth rate versus antibiotic concentration; B, Reciprocal of growth rate plotted against reciprocal of dihydrostreptomycin concentration.

\section{Table I. Effect of carbon source on the antibiotic requirement for growth of the streptomycin-dependent mutant of Escherichia coli $B$}

Growth experiments were performed as described in Methods. Each carbon source was initially $0.4 \%(w / v) . V_{\max }$ is the growth rate on non-limiting antibiotic, $K_{D H S m}$ is the antibiotic concentration required to give one-half the maximum growth rate, calculated as shown in Fig. 2 B.

$\begin{array}{ccc}\text { Carbon source } & \begin{array}{c}\mathrm{V}_{\max } \\ \left(\mathbf{h r}^{-1}\right)\end{array} & \begin{array}{c}\mathbf{K}_{\mathbf{D H S m}} \\ (\mu \mathrm{g} . / \mathrm{ml} .)\end{array} \\ \text { Gluconate } & 0.9 \mathrm{I} 4 & \mathrm{I} 2.6 \\ \text { Glucose } & 0.66 \mathrm{I} & 5.3 \\ \text { Glycerol } & 0.558 & 2.0 \\ \text { Lactate } & 0.485 & \mathrm{I} \cdot 5\end{array}$

Effect of growth on limiting-dihydrostreptomycin on the formation of enzymes of carbohydrate metabolism. Table 2 records the specific activities of several catabolite repression-sensitive enzymes of carbohydrate metabolism (Coukell \& Polglase, I $969 b$ ) which were determined after growth on various carbon sources in the presence of growth-rate-limiting or non-limiting concentrations of dihydrostreptomycin. The specific activities of two glucose-insensitive enzymes-glucokinase and glucose-6phosphate dehydrogenase (Coukell \& Polglase, 1969 b)-were determined in the same extracts. In general, the specific activities of the catabolite repression-sensitive enzymes (AHA synthetase, isocitrate dehydrogenase, aconitase, fumarase and citrate synthase) 
from cells grown in the presence of $100 \mu \mathrm{g}$. dihydrostreptomycin $/ \mathrm{ml}$. were lowest when $\mathbf{K}_{\mathrm{DHsm}}$ values for the various carbon sources were highest. For any particular carbon source, except gluconate, the percentage repression of the glucose-sensitive enzymes (isocitrate dehydrogenase excluded) from cells grown with $3 \mu \mathrm{g}$. dihydrostreptomycin $/ \mathrm{ml}$. compared with cells grown with $100 \mu \mathrm{g}$. antibiotic/ml. was greater the higher the value of $\mathrm{K}_{\mathrm{DHSm}}$. Gluconate exhibited a relatively high degree of repression even when the dihydrostreptomycin concentration was non-limiting (100 $\mu \mathrm{g} . / \mathrm{ml}$.) (Table 2). Aconitase was repressed when streptomycin-dependent cells were grown on glucose or gluconate at a concentration of $3 \mu \mathrm{g}$. dihydrostreptomycin $/ \mathrm{ml}$. but was derepressed when they were grown on glycerol or lactate at the same antibiotic concentration.

Table 2. The effect of dihydrostreptomycin concentration on enzyme formation on different carbon sources in streptomycin-dependent Escherichia coli $B$

Carbon sources were initially $0.4 \%(\mathrm{w} / \mathrm{v})$. The cultures were grown on either a limiting $(3 \mu \mathrm{g} . / \mathrm{ml}$.) or a non-limiting (100 $\mu \mathrm{g} . / \mathrm{ml}$.) concentration of dihydrostreptomycin (DHSm). The procodures for growing and harvesting cultures, preparing sonic extracts, and assaying enzymes are described in Methods. Specific activities are expressed as units of enzyme/mg. bacterial protein.

\begin{tabular}{|c|c|c|c|c|c|}
\hline & \multirow{2}{*}{$\underset{(\mu \mathrm{g} . / \mathrm{ml} .)}{\mathrm{DHSm}}$} & \multicolumn{4}{|c|}{$\begin{array}{l}\text { (percentage in parenthesis) } \\
\text { with carbon source }\end{array}$} \\
\hline & & Gluconate & Glucose & Glycerol & Lactate \\
\hline AHA synthetase & $\begin{array}{c}100 \\
3\end{array}$ & $\begin{array}{l}6 \cdot 0 \\
I \cdot 5(75)\end{array}$ & $\begin{array}{l}\text { I } 1 \cdot 4 \\
2 \cdot 5(78)\end{array}$ & $\begin{array}{l}11 \cdot 0 \\
7 \cdot 5(32)\end{array}$ & $\begin{array}{l}12 \cdot 9 \\
11 \cdot 4(12)\end{array}$ \\
\hline Isocitric dehydrogen.ıse & $\begin{array}{r}100 \\
3\end{array}$ & $\begin{array}{l}564 \\
607(-8)\end{array}$ & $\begin{array}{l}547 \\
462(\mathrm{I} 6)\end{array}$ & $\begin{array}{l}800 \\
883(-I I)\end{array}$ & $\begin{array}{l}817 \\
815(0)\end{array}$ \\
\hline Aconitase & $\begin{array}{r}100 \\
3\end{array}$ & $\begin{array}{l}270 \\
61(77)\end{array}$ & $\begin{array}{l}216 \\
128(4 I)\end{array}$ & $\begin{array}{l}478 \\
530(-11)\end{array}$ & $\begin{array}{l}434 \\
638(-47)\end{array}$ \\
\hline Fumarase & $\begin{array}{r}100 \\
3\end{array}$ & $\begin{array}{l}552 \\
\text { I } 34(76)\end{array}$ & $\begin{array}{l}1942 \\
670(65)\end{array}$ & $\begin{array}{l}2260 \\
1590(30)\end{array}$ & $\begin{array}{l}2170 \\
1935 \text { (II) }\end{array}$ \\
\hline Citrate synthase & $\begin{array}{r}100 \\
3\end{array}$ & $\begin{array}{r}197 \\
84(57)\end{array}$ & $\begin{array}{l}320 \\
89(72)\end{array}$ & $\begin{array}{l}523 \\
426(19)\end{array}$ & $\begin{array}{l}365 \\
287(21)\end{array}$ \\
\hline $\begin{array}{l}\text { Glucose-6-phosphate } \\
\text { dehydrogenase }\end{array}$ & $\begin{array}{r}100 \\
3\end{array}$ & $\begin{array}{l}125 \\
118(6)\end{array}$ & $\begin{array}{l}109 \\
109(0)\end{array}$ & $\begin{array}{l}120 \\
122(-2)\end{array}$ & $\begin{array}{l}79 \\
70(11)\end{array}$ \\
\hline Glucokinase & $\begin{array}{r}100 \\
3\end{array}$ & $\begin{array}{l}79 \\
77(3)\end{array}$ & $\begin{array}{l}115 \\
92(20)\end{array}$ & $\begin{array}{l}81 \\
79(2)\end{array}$ & $\begin{array}{l}75 \\
76(-I)\end{array}$ \\
\hline
\end{tabular}

Glucokinase and glucose-6-phosphate dehydrogenase formation were relatively unaffected by dihydrostreptomycin-limitation. Although the specific activities of both enzymes varied slightly on the different carbon sources, these differences showed no correlation with either the antibiotic requirements or the growth rates of the streptomycin-dependent cultures (Table 2).

To determine whether the enhanced catabolite repression resulting from growth on gluconate was a general characteristic of Escherichia coli strain B, or a specific property of the streptomycin-dependent mutant, the specific activity of AHA synthetase was determined in extracts of streptomycin-sensitive and streptomycin-dependent cultures grown on glucose and on gluconate (Table 3). As shown previously (Coukell \& Polglase, $1969 b$ ), the AHA synthetase of the streptomycin-dependent mutant was derepressed in extracts of glucose-grown cells, when compared with the wild-type 
organism. In extracts of the streptomycin-dependent mutant grown on gluconate, however, AHA synthetase was repressed almost as strongly as was this enzyme in the wild-type organism grown on either glucose or gluconate. Furthermore, the growth rate of the streptomycin-dependent culture was considerably higher on gluconate than on'glucose, while the streptomycin-sensitive culture grew at the same rate on either carbon source (Table 3). Cell-yield experiments, however, indicated that gluconate metabolism, like glucose metabolism, was $38 \%$ less efficient in the mutant than in the wild-type organism (Coukell \& Polglase, unpublished observation). Therefore, the enhanced growth rate and the increased catabolite repression observed in the streptomycin-dependent mutant growing on gluconate did not result from an increased yield of energy from this carbon source.

\section{Table 3. Growth rates of Escherichia coli strains on glucose and gluconate and the formation of AHA synthetase}

Cultures were grown aerobically at $37^{\circ}$ on salts medium supplemented as indicated. The media for growth of the streptomycin-dependent cultures were supplemented with dihydrostreptomycin (I mg./ml.). AHA synthetase was assayed in crude sonic extracts (see Methods).

$\begin{array}{cccc}\text { Strain } & \begin{array}{c}\text { Carbon source } \\ (0.4 \%, \mathrm{w} / \mathrm{v})\end{array} & \begin{array}{c}\text { Growth rate } \\ \left(\mathrm{hr}^{-1}\right)\end{array} & \begin{array}{c}\text { AHA synthetase } \\ (\mu \text { moles acetoin/ } \\ \text { mg. protein/hr) }\end{array} \\ \text { Streptomycin-sensitive } & \text { Glucose } & \text { I.I I } & 5 \cdot 00 \\ \text { Streptomycin-dependent } & \text { Gluconate } & \mathrm{I} \cdot \mathrm{II} & 5.90 \\ & \text { Glucose } & 0.66 & \mathrm{I} \cdot \mathrm{I} \\ & \text { Gluconate } & 0.8 \mathrm{I} & 7 \cdot 85\end{array}$

Relationship between growth rate and enzyme synthesis in streptomycin-dependent cells grown with limiting-antibiotic. A direct relationship was observed between the diminished growth rate in the presence of limiting-antibiotic and the degree of repression of certain glucose-sensitive enzymes. This relationship is illustrated in Fig. 3 for AHA synthetase and fumarase activities in extracts of glucose and gluconate-grown cells. In general, both growth rate and enzyme formation were lower on gluconate than on glucose at the same antibiotic concentration. Not all glucose-sensitive enzymes exhibited this relationship, however. While the degree of repression of citrate synthase under these conditions often correlated with the growth rate of the culture, aconitase and isocitric dehydrogenase rarely displayed this parallelism. Except for fumarase, this relationship was seldom observed in cultures grown on the poor carbon sources glycerol and lactate.

Response of catabolite repression-sensitive enzymes of antibiotic-depleted cells to dihydrostreptomycin supplementation. After 10 to $\mathrm{I} 2 \mathrm{hr}$ of growth in medium containing glucose but no antibiotic, the streptomycin-dependent cells exhibited the filamentous growth which is characteristic of antibiotic depletion (Delaporte, 1949). The addition of dihydrostreptomycin ( $\mathrm{I} \mathrm{mg} . / \mathrm{ml}$.) to antibiotic-starved cultures resulted in a progressive breakdown of the elongated cells which was usually complete within $3 \mathrm{hr}$. The effect of dihydrostreptomycin-supplementation of antibiotic-depleted cells on the formation of certain glucose-sensitive enzymes in strain DB is shown in Table 4. The difference in specific activities of these enzymes in extracts of antibiotic-depleted and antibiotic-supplemented cells after $3 \mathrm{hr}$ indicated that the synthesis of these enzymes undergoes a rapid and dramatic derepression during this period. The glucose- 
insensitive enzymes, glucokinase and glucose-6-phosphate dehydrogenase, were relatively unaffected by dihydrostreptomycin-depletion or by the subsequent antibioticsupplementation.

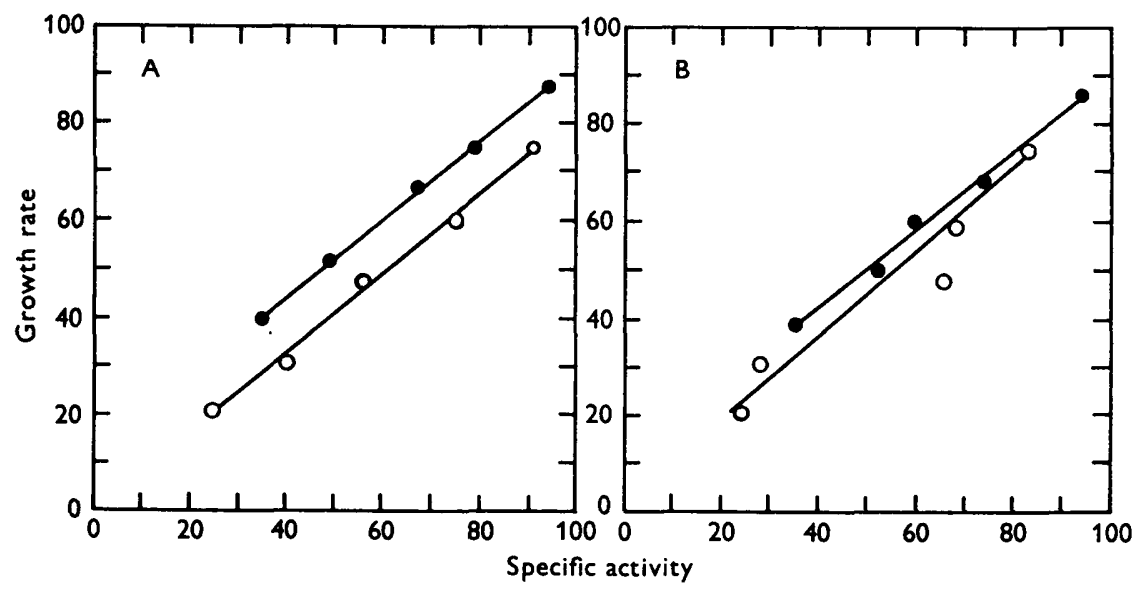

Fig. 3. Relationship between the decrease in growth rate and enzyme repression in antibioticlimited cultures of streptomycin-dependent Escherichia coli B. Growth experiments were carried out as described in Methods. Glucose (O) or gluconate (O) were added to give an initial concentration of $0.4 \%(w / v)$. Growth rates and specific activities are expressed as percentages of the values obtained with cultures grown on $100 \mu \mathrm{g}$. dihydrostreptomycin/ $\mathrm{ml}$. The antibiotic concentrations employed were $25,15,10,5$ and $3 \mu \mathrm{g} . / \mathrm{ml}$., respectively. A, AHA synthetase; B, Fumarase.

Table 4. Effect of antibiotic-supplementation on enzyme formation in streptomycin-depleted cells grown on glucose

Preparation of antibiotic-depleted streptomycin-dependent Escherichia coli and methods of enzymo assay are described in Methods. Supplemented cells received I mg. dihydrostreptomycin $/ \mathrm{ml}$. $3 \mathrm{hr}$ before harvesting.

\begin{tabular}{|c|c|c|c|}
\hline \multirow[b]{2}{*}{ Enzyme } & \multicolumn{2}{|c|}{$\begin{array}{c}\text { Specific activity } \\
\text { (units/mg. of protein) }\end{array}$} & \multirow{2}{*}{$\begin{array}{c}\text { Ratio, } \\
\text { supplemented: } \\
\text { depleted }\end{array}$} \\
\hline & Depleted & Supplemented & \\
\hline AHA synthetase & $I \cdot 68$ & $11 \cdot 7$ & $7 \cdot 0$ \\
\hline Fumarase & 200 & I622 & $8 \cdot 1$ \\
\hline Aconitase & 34.4 & 182 & $5 \cdot 3$ \\
\hline socitric dehydrogenase & 183 & 490 & $2 \cdot 7$ \\
\hline Citrate synthase & I 18 & 426 & $3 \cdot 6$ \\
\hline $\begin{array}{l}\text { Glucose-6-phosphate } \\
\text { dehydrogenase }\end{array}$ & $75 \cdot 2$ & $81 \cdot 4$ & $\mathbf{I} \cdot \mathbf{I}$ \\
\hline Glucokinase & $64 \cdot 3$ & $91 \cdot 6$ & $1 \cdot 4$ \\
\hline
\end{tabular}

\section{DISCUSSION}

The value obtained for $\mathrm{K}_{\mathrm{DHSm}}$ depended on the nature of the carbon source, being highest for energy-rich, rapidly metabolizable compounds such as gluconate and glucose. This finding contrasts with a related study by Spotts (1962) on streptomycindependent mutants of Escherichia coli $\mathrm{K} 12$, in which the growth rates of these mutants on glycerol were a direct function of the streptomycin concentration up to 
approximately $100 \mu \mathrm{g} . / \mathrm{ml}$., at which value ('critical concentration') streptomycin was no longer the rate-limiting factor. When glucose was the carbon source, streptomycin remained rate-limiting up to about $250 \mu \mathrm{g}$./ml. At rate-limiting concentrations of antibiotic, however, growth rates were independent of the nature of the carbon source (Spotts, 1962).

Goodman \& Spotts (1967) reported that the synthesis of both inducible and constitutive $\beta$-galactosidase and of constitutive alkaline phosphatase were inhibited during the growth of streptomycin-dependent strains of Escherichia coli transferred to medium containing no added antibiotic. They attributed some, but not all, of this inhibition to an increase in catabolite repression in the antibiotic-deprived cells. They suggested that, in addition to inhibition of enzyme synthesis by catabolite repression, enzyme inhibition could occur randomly due to the misreading of certain codons by the abnormal streptomycin-deficient, streptomycin-dependent ribosomes. However, they were unable to detect cross-reacting material by serological methods or to find any other evidence for infidelity of translation in vivo, either in the presence or absence of streptomycin. The results of the present investigation suggest that catabolite repression without misreading can explain the enzyme imbalance (Tables 2 , 4). All of the glucose-sensitive enzymes examined were repressed whereas glucoseinsensitive enzymes were not affected by growth with limiting antibiotic. Furthermore, dihydrostreptomycin supplementation of antibiotic-starved cells resulted in a rapid and specific derepression of the catabolite repression-sensitive enzymes (Table 4).

Glucose generally is considered to be the most effective source of catabolite corepressor (Magasanik, I96I). Therefore, it was surprising that growth of the streptomycin-dependent mutant (but not of the wild-type parent strain) on gluconate resulted in a higher rate of growth and stronger catabolite repression than when the same organism was grown on glucose (Table 3). This response was not due to a higher yield of energy from gluconate since the yield of streptomycin-dependent cells was the same with both carbon sources (Coukell \& Polglase, unpublished observation). Gluconate therefore must be metabolized more rapidly than glucose by this mutant. Eisenberg \& Dobrogosz (1967) reported that, in Escherichia coli, gluconate is metabolized via the inducible Entner-Doudoroff pathway rather than by the hexose monophosphate pathway, the major aerobic route of glucose dissimilation. Since pyruvate is an early product of the Entner-Doudoroff pathway, the rate of aerobic pyruvate-coupled energy formation may be higher in the antibiotic-dependent mutant growing on gluconate than in the same mutant growing on glucose. An increase such as this in rate of energy formation could explain both the higher rate of growth and the stronger catabolite repression observed in gluconate-grown cultures of the streptomycin-dependent mutant.

The current hypothesis concerning the mechanism of action of streptomycin (or dihydrostreptomycin) has been deduced mainly from studies of ribosomal preparations of streptomycin-sensitive and resistant (indifferent) cells (Pestka, 1967). Streptomycin has been shown to affect reactions of protein synthesis in ribosomal preparations from streptomycin-sensitive cells whereas these reactions were not affected in similar preparations from streptomycin-resistant cells. The results presented here indicate that catabolite repression may play an important role in establishing the quantitative requirement for antibiotic for growth of streptomycin-dependent Escherichia coli. In order to incorporate these results into the hypothesis which indicates protein 
synthesis to be the primary process affected by streptomycin, one may postulate that, in vivo, the primary effect of the antibiotic on protein synthesis is augmented by the secondary effect of catabolite repression. In the streptomycin-dependent cells the limitation of antibiotic initially may impair ribosomal function without immediately affecting catabolic processes. The result of limitation of anabolism while catabolism continues would be severe repression of the glucose-sensitive enzymes ultimately resulting in a decreased rate of both catabolic and anabolic reactions and leading to a decrease in the growth rate of the organism.

\section{REFERENCES}

Bragg, P. D. \& Polglase, W. J. (1963). Electron transport components of streptomycin-dependent Escherichia coli. J. Bact. 86, 544.

Coukell, M. B. \& Polglase, W. J. (1965). Acetolactate formation by streptomycin mutants of Escherichia coli. Can. J. Microbiol. Ir, 905.

Coukell, M. B. \& Polglase, W. J. (1969a). Repression by glucose of acetohydroxy acid synthetase in Escherichia coli B. Biochem. J. III, 273.

Coukell, M. B. \& Polglase, W. J. (1969b). Relaxation of catabolite repression in streptomycindependent Escherichia coli. Biochem. J. III, 279.

DAvis, B. D. \& MingIOLI, E. S. (1950). Mutants of Escherichia coli requiring methionine or vitamin $B_{12}$. J. Bact. 60, 17.

DelaPorTe, B. (1949). Yb. Carnegie Instn. Wash. 48, 166.

EISENBERG, R. C. \& Dobrogosz, W. J. (1967). Gluconate metabolism in Escherichia coli. J. Bact. 93, $94 \mathrm{I}$.

Goodman, R. E. \& SpotTs, C. R. (1967). Effect of streptomycin deprivation on enzyme synthesis in streptomycin-dependent Escherichia coli. J. Bact. 94, 1154.

Hanson, R. S. \& Cox, D. P. (1967). Effect of different nutritional conditions on the synthesis of tricarboxylic acid cycle enzymes. J. Bact. $93,1777$.

Lowry, O. H., Rosebrough, N. J., Farr, A. L. \& Randall, R. J. (I95I). Protein measurement with the Folin phenol reagent. J. biol. Chem. 193, 265.

Magasanix, B. (196I). Catabolite repression. Cold Spring Harb. Symp. quant. Biol. $26,249$.

PestKa, S. (1967). The action of streptomycin on protein synthesis in vitro. Bull. N.Y. Acad. Med. 43, 126.

Polglase, W. J. (1966). Regulation of acetohydroxy acid synthetase in streptomycin-dependent Escherichia coli. Can. J. Biochem. 44, 599.

SpotTs, C. R. (1962). Physiological and biochemical studies on streptomycin dependence in Escherichia coli. J. gen. Microbiol. 28, 347.

Umbarger, H. E. \& Davis, B. C. (1962). Pathways of amino acid biosynthesis. In The Bacteria. Ed. by I. C. Gunsalus and R. Y. Stanier, vol. 3, p. 208. New York: Academic Press, Inc. 